\title{
Processing, Microstructure and Dielectric Properties of the $\mathrm{Bi}_{5} \mathrm{Ti}_{3} \mathrm{FeO}_{15}$ Ceramic
}

\author{
J. RymarczyK ${ }^{a}$, G. Dercz ${ }^{b}$ And J. ILCZuK ${ }^{a * *}$
}

${ }^{a}$ Department of Material Science

Faculty of Computer Science and Material Science, University of Silesia

Żeromskiego 3, 41-200 Sosnowiec, Poland

${ }^{b}$ Institute of Material Science, University of Silesia

Bankowa 12, 40-007 Katowice, Poland

The aim of the present work is the analysis of microstructure, dielectric permittivity and thermal properties analysis of $\mathrm{Bi}_{5} \mathrm{Ti}_{3} \mathrm{FeO}_{15}$ ceramics obtained by two methods. The studied $\mathrm{Bi}_{5} \mathrm{Ti}_{3} \mathrm{FeO}_{15}$ ceramics were prepared by conventional synthesis and hot uniaxial pressing reaction from the conventional mixture of oxides, viz. $\mathrm{TiO}_{2}, \mathrm{Fe}_{2} \mathrm{O}_{3}, \mathrm{Bi}_{2} \mathrm{O}_{3}$. The studied material has layered perovskite like structures, first described by Aurivillius in 1949 and Subbaro in 1969. The ceramic $\mathrm{Bi}_{5} \mathrm{Ti}_{3} \mathrm{FeO}_{15}$ is known to contain a series of compounds with the general formula: $\mathrm{Bi}_{m+1} \mathrm{Fe}_{m-3} \mathrm{Ti}_{3} \mathrm{O}_{3 m+3}$. The $\mathrm{X}$-ray diffraction methods were used for qualitative phase analysis of studied samples. The morphology was analyzed by scanning electron microscopy method. The thermal properties of the studied materials were measured using the differential thermal analysis at a constant heating rate of $15 \mathrm{~K} / \mathrm{min}$ under an argon protective atmosphere. Thermal dependence of dielectric permittivity was studied between room temperature and $1137 \mathrm{~K}$.

PACS numbers: 77.84.-s, 81.20.Ev, 77.84.-s, 81.05.Je, 61.05.cp, 68.37.Ef

\section{Introduction}

The $\mathrm{Bi}_{5} \mathrm{Ti}_{3} \mathrm{FeO}_{15}$ (BTF) multiferroic ceramic is used while constructing different types of memory elements as for example a shape or information [1]. The $\mathrm{Bi}_{5} \mathrm{Ti}_{3} \mathrm{FeO}_{15}$ ceramic belongs to ferroelectromagnetics, characterized by presence of simultaneous magnetic and ferroelectric ordering [2-6]. The term of a multiferroic was introduced by Schmid in 1994 and it describes materials showing at least two ferroic states simultaneously in the same phase. In the multiferroic materials $M_{\mathrm{s}}$ (the parameter of the magnetic system ordering), $P_{\mathrm{s}}$ (the parameter of the electric system ordering) and $\eta_{\mathrm{s}} P_{\mathrm{s}}$ (the parameter of the elastic-magnetic system ordering) can be changed both by a magnetic field $(H)$, an electric field $(E)$ and by a mechanical stress $(\sigma)$ [8-10].

${ }^{*}$ corresponding author; e-mail: jilczuk@us.edu.pl 
Majority of ferroelectromagnetics have a layer perovskite-like structure. Structures of that type were discovered for the first time by Aurivillius in 1949 [1] and Subbaro described them in 1969 by a general formula in a form of

$$
\mathrm{A}_{m-1} \mathrm{Bi}_{2} \mathrm{~B}_{m} \mathrm{O}_{33+3},
$$

where big cations $\mathrm{A}$ are: $\mathrm{Ba}, \mathrm{Sr}, \mathrm{Ca}, \mathrm{Bi}, \mathrm{Pb}$, whereas $\mathrm{B}$ ones are cations of transient metals $\mathrm{Ti}, \mathrm{Nb}, \mathrm{Ta}, \mathrm{Mo}, \mathrm{W}, \mathrm{Fe}, \mathrm{Mn}, m$ designates a number of perovskite layers along the thickness [6-13]. It means that the layers made of chains of oxygen octahedrons with thickness $m$ separated with bismuth-oxygen layers interleave with each other.

By introducing $\mathrm{Fe}^{3+}$ iron cations into place $\mathrm{B}$ a group of compounds called ferroelectromagnetics with a general formula can be obtained

$$
\mathrm{Bi}_{4} \mathrm{Bi}_{m-3} \mathrm{Ti}_{3} \mathrm{Fe}_{m-3} \mathrm{O}_{3 m+3} \quad(m=1,2,3,4,5,8)
$$

(see Refs. [8-14]). The $\mathrm{Bi}_{5} \mathrm{Ti}_{3} \mathrm{FeO}_{15}$ ceramic is a model ferroelectromagnetic of that type [15-17].

An aim of this work was to develop a technology to produce a biferroic ceramic of a type $\mathrm{Bi}_{5} \mathrm{Ti}_{3} \mathrm{FeO}_{15}(m=4)$ showing a layer perovskite-like structure and to characterize its microstructure and dielectric properties.

\section{Experimental}

The test material was prepared in two stages (Fig. 1). In the first stage it was obtained as a result of the reaction in the solid phase synthesis, which was conducted by two methods. The first method was a synthesis from the refined pressed mixture of the $\mathrm{Bi}_{2} \mathrm{O}_{3}, \mathrm{TiO}_{2}$, and $\mathrm{Fe}_{2} \mathrm{O}_{3}$ simple oxides. A synthesis from a mixture of the $\mathrm{BiFeO}_{3}$ and $\mathrm{Bi}_{4} \mathrm{Ti}_{3} \mathrm{O}_{12}$ complex oxides constituted the second stage. In both cases the synthesis reaction was conducted at $800^{\circ} \mathrm{C}$ temperature in $5 \mathrm{~h}$ time. The synthesized powders were subjected to pressing in a shape of disks with a $10 \mathrm{~mm}$ diameter and compacting by a method of free sintering and hot pressing, which was the second stage of a technology to obtain test material. The free sintering process was conducted twice for $5 \mathrm{~h}$ at $1040^{\circ} \mathrm{C}$ (the sample described as BTF1 and BTF2) and hot pressing for $1 \mathrm{~h}$ at $850^{\circ} \mathrm{C}$ under $5 \mathrm{MPa}$ pressure (the sample described as BTF3 and BTF4).

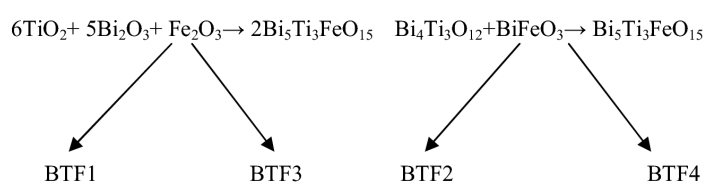

Fig. 1. A diagram of a technology to obtain the $\mathrm{Bi}_{5} \mathrm{Ti}_{3} \mathrm{FeO}_{15}$ multiferroic ceramic $(m=4)$ by the method of free sintering (BTF1, BTF3) and hot pressing (BTF2, BTF4).

The phase analysis was carried out by an X-Pert Philips diffractometer equipped with a curved graphite monochromator on the diffracted beam and with following slits (in the sequence from the copper tube to the proportional 
counter): Soller $\left(2^{\circ}\right)$, divergence $\left(1 / 2^{\circ}\right)$, antiscatter $\left(1 / 2^{\circ}\right)$, Soller $\left(2^{\circ}\right)$ and receiving $(0.15 \mathrm{~mm})$. It was supplied with current intensity of $30 \mathrm{~mA}$ and voltage of $40 \mathrm{kV}$. The length of radiation $\left(\lambda \mathrm{Cu} K_{\alpha}\right)$ was $1.54178 \AA$. The data of diffraction lines were recorded by "step-scanning" method in $2 \theta$ range from $10^{\circ}$ to $140^{\circ}$ and $0.05^{\circ}$ step.

The SEM (HITACHI S-4700 NORAN Vantage) method and energy dispersion spectroscopy (EDS) technique were applied for the analysis of ceramic sample morphology and their chemical composition, respectively.

\section{Results}

Optimization of technological conditions was performed by analyzing a phase composition, a microstructure, a chemical composition and density. It enabled to determine the optimum method and conditions of the $\mathrm{Bi}_{5} \mathrm{Ti}_{3} \mathrm{FeO}_{15}$ synthesis.

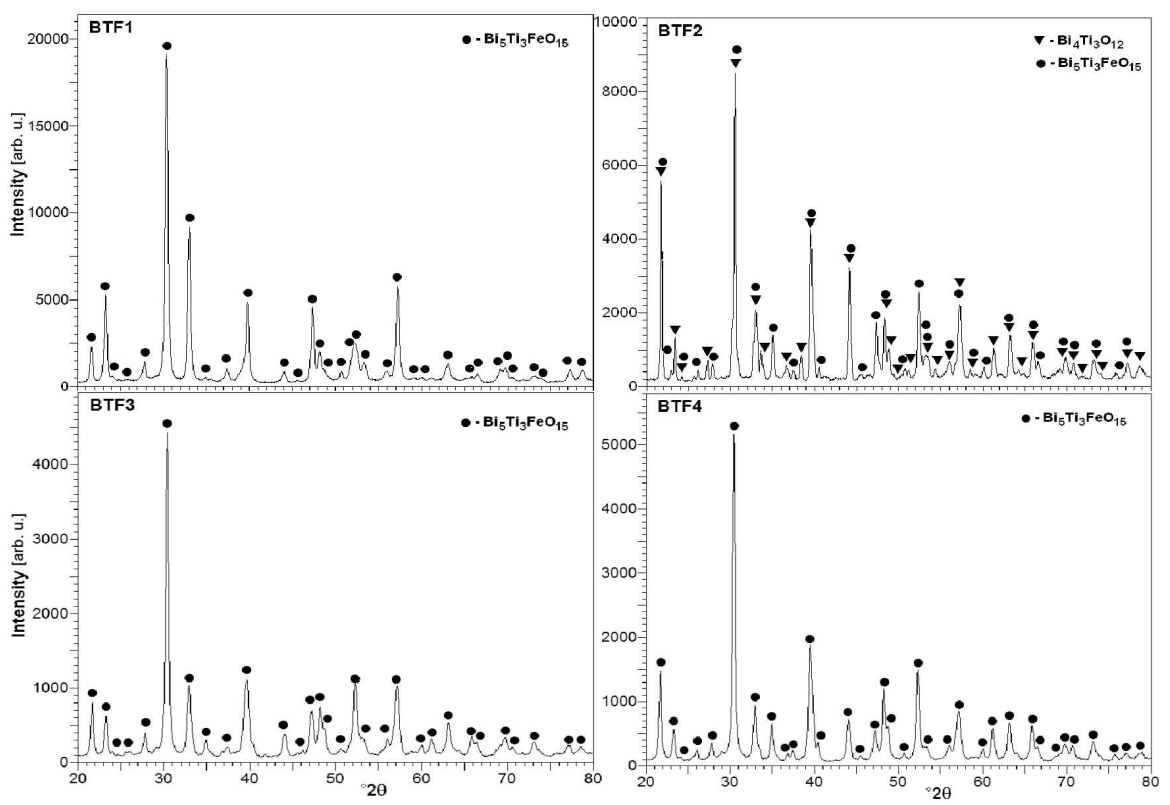

Fig. 2. Diffraction patterns of the BTF ceramic obtained as a result of compacting by a method of free sintering (BTF1, BTF2) and hot pressing (BTF3, BTF4).

A qualitative phase analysis showed that the BTF solid solution crystallized as the single phase $\mathrm{Bi}_{5} \mathrm{Ti}_{3} \mathrm{FeO}_{15}$ (ICDD PDF 82-0063) ceramic, both during the synthesis of a mixture of stoichiometrically selected simple oxides by the method of free sintering (BTF1), hot pressing (BTF3) and from the solid solutions by the hot pressing method (BTF4) (Fig. 2). The two-phase ceramic, in which besides $\mathrm{Bi}_{5} \mathrm{Ti}_{3} \mathrm{FeO}_{15}$ (ICDD PDF 82-0063) there was a $\mathrm{Bi}_{4} \mathrm{Ti}_{3} \mathrm{O}_{12}$ (ICDD PDF 35-0795) phase, was obtained by the ceramic synthesis from the complex oxides (BTF2) by the free sintering method (Fig. 2). 
The $\mathrm{Bi}_{5} \mathrm{Ti}_{3} \mathrm{FeO}_{15}$ ceramic has symmetry of an orthorhombic system and the Fmm2 space group. The ceramic discs were compacted using different technological conditions of free sintering and hot pressing. On basis of tests of experimental density the optimum compacting temperature of the BTF ceramic was determined (Fig. 3). It has been shown that in spite of the shorter sintering time and lower temperature used the hot pressing process enables to obtain a BTF multiferroic ceramic with high density $\left(7.23 \mathrm{~g} / \mathrm{cm}^{3}\right)$ (Fig. 3).

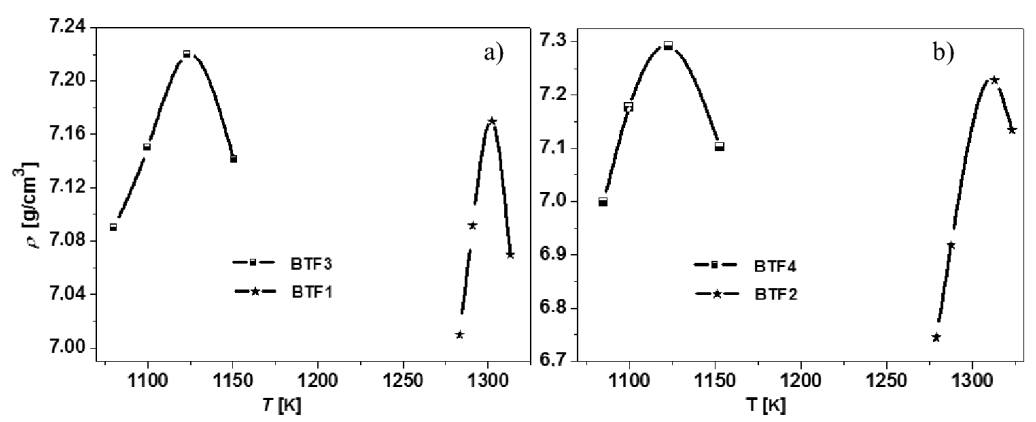

Fig. 3. Density of the BFT ceramic depending on the method and temperature used: (a) obtained from a mixture of simple oxides and (b) from a mixture of complex oxides.

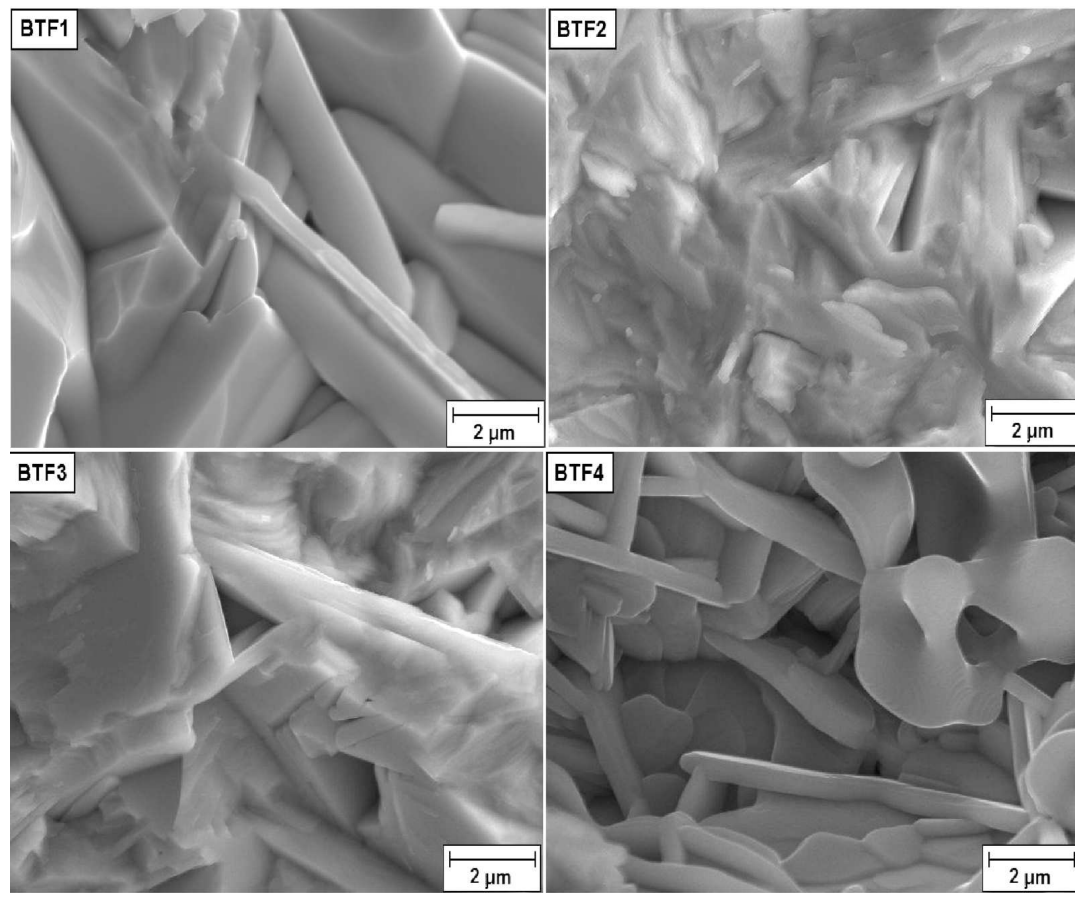

Fig. 4. Microstructures of fractures of the BFT ceramic obtained as a result of compacting by a method of free sintering (BTF1, BTF2) and hot pressing (BTF3, BTF4). 
TABLE

Results of the EDS chemical analysis for the $\mathrm{Bi}_{5} \mathrm{Ti}_{3} \mathrm{FeO}_{15}$ ceramic specimens.

\begin{tabular}{c|c|c|c}
\hline \hline \multirow{2}{*}{ Sample } & \multicolumn{3}{|c}{ Elements } \\
\cline { 2 - 4 } & $\mathrm{Ti} \%$ & $\mathrm{Fe} \%$ & $\mathrm{Bi} \%$ \\
\hline BTF1 & 35.21 & 11.69 & 53.10 \\
BTF2 & 40.80 & 12.08 & 47.12 \\
BTF3 & 40.53 & 14.72 & 44.75 \\
BTF4 & 42.94 & 14.82 & 42.24
\end{tabular}

Morphology of fractures of the $\mathrm{Bi}_{5} \mathrm{Ti}_{3} \mathrm{FeO}_{15}$ ceramic compacted by a method of free sintering and hot pressing is presented in Fig. 4. The $\mathrm{Bi}_{5} \mathrm{Ti}_{3} \mathrm{FeO}_{15}$ ceramic shows lamellar grains, overlapping each other, which is characteristic of layer structures. The presented images and results of the experimental density tests confirm necessity to use a compacting method by the hot pressing, to obtain the BTF ceramic with higher density and lower porosity in relation to a free sintered ceramic. The EDS analysis made for a BTF ceramic sinter with an area of dimensions $20 \mu \mathrm{m} \times 20 \mu \mathrm{m}$ confirms the experimentally assumed quantitative composition. Percentage content of elements for particular materials is presented in Table.

The ferroelectric Curie temperatures $\left(T_{\mathrm{CE}}\right)$ were determined on the basis of the $\epsilon(T)$ function maxima. In a case of the $\mathrm{Bi}_{5} \mathrm{Ti}_{3} \mathrm{FeO}_{15}$ multiferroic ceramic with $m=4$ obtained both as a result of a reaction from simple oxides and from complex oxides two maxima were observed on the electric permittivity curve (Fig. 5). The first one occurs at a temperature of about $1048 \mathrm{~K}$ and is typical of the ferroelectricparaelectric change. The second one is present at a temperature of about $700 \mathrm{~K}$ and is responsible for a magnetic change (ferroelectric-antiferromagnetics).
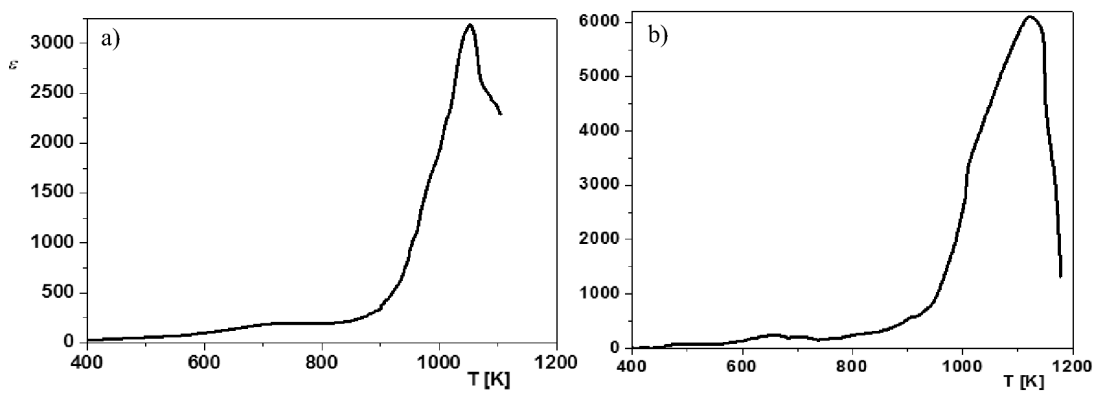

Fig. 5. Dependences of the electric permittivity on the temperature for BTF1 (a) and BTF2 (b). 


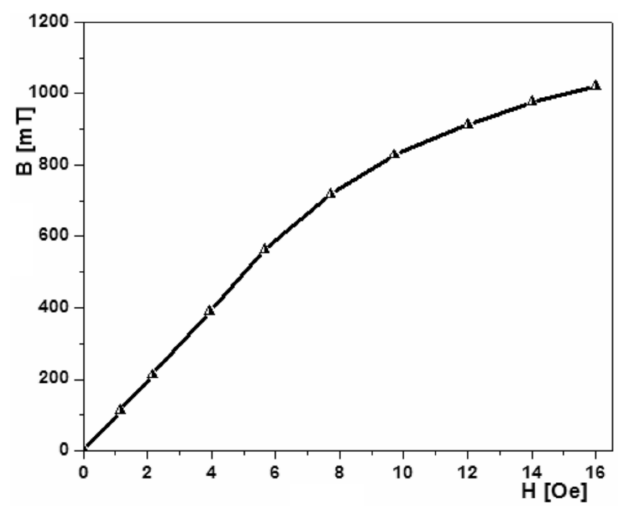

Fig. 6. A curve of the original magnetization.

Classifying the BTF ceramic into multiferroics was possible by proving also existence of magnetic origin effects in it. A curve of the original magnetization for $\mathrm{Bi}_{5} \mathrm{Ti}_{3} \mathrm{FeO}_{15}$ is presented in Fig. 6 .

\section{Conclusions}

Synthesis by hot pressing enabled to obtain a single phase multiferroic BTF ceramic with higher density than by the free sintering process. Occurrence of a ferroelectric state in the obtained ceramic was found by presence of a characteristic maximum $(\epsilon)$ of electric permittivity peak on the $\epsilon(T)$ curves. The obtained original magnetization curve confirms presence of both ferroelectric and magnetic properties, for that reason the $\mathrm{Bi}_{5} \mathrm{Ti}_{3} \mathrm{FeO}_{15}$ ceramic can be classified into a group of compounds so-called multiferroics.

\section{Acknowledgments}

The financial support for this work was provided by the Ministry of Science and Higher Education, Poland, under grant no. N50714231/3568 (2006-2009).

\section{References}

[1] N.A. Lomanova, M.I. Morozov, V.L. Ugolkov, V.V. Gusarov, Inorg. Mater. 42, 18995 (2006).

[2] B. Aurivillius, Ark. Kemi. 1, 463 (1949).

[3] E.C. Subbaro, J. Phys. Chem. Solids 23, 665 (1977).

[4] E.C. Subbaro, Phys. Rev. 122, 804 (1961).

[5] E.C. Subbaro, J. Am. Ceram. Soc. 45, 166 (1962).

[6] G.A. Smolenskii, V.A. Isupov, A.I. Agranovskaya, Fiz. Tverd. Tela 1, 169 (1959).

[7] G.A. Smolenskii, V.A. Isupov, A.I. Agranovskaya, Fiz. Tverd. Tela 3, 896 (1963).

[8] H. Schmid, Ferroelectrics 162, 317 (1994). 
[9] A.R. James, G.S. Kumar, M. Kumar, S.V. Suryanarayana, T. Bhimasankaram, Mod. Phys. Lett. B 11, 633 (1997).

[10] M. Kumar, A. Srinivas, G.S. Kumar, S.V. Suryanarayana, Solid State Commun. 104, 741 (1997).

[11] J.A. Deverin, Ferroelectrics 19, 9 (1978).

[12] M. Plonska, Z. Surowiak, Mol. Quant. Acoust. 27, 207 (2006).

[13] J. Rymarczyk, D. Machura, J. Ilczuk, Eur. Phys. J., to be published.

[14] J. Ilczuk, D. Machura, J. Rymarczyk, Mol. Quant. Acoust. 28, 107 (2007).

[15] A. Srinivas, D.W. Kim, K.S. Hong, S.V. Suryanarayana, Mater. Res. Bull. 39, 55 (2004).

[16] M. Plonska, Z. Surowiak, Mol. Quant. Acoust. 28, 253 (2007).

[17] C.H. Hervoches, A. Snedden, R. Riggs, S.H. Kilcoyne, P. Manuel, P. Lightfoot, J. Solid State Chem. 164, 280 (2002). 